Article

\title{
Health and Scientific Frames in Online Communication of Tick-Borne Encephalitis: Antecedents of Frame Recognition
}

\author{
Sarah Kohler ${ }^{1, *}$ and Isabell Koinig ${ }^{2}$ \\ ${ }^{1}$ Department of Science Communication, Karlsruhe Institute of Technology, 76131 Karlsruhe, Germany; \\ E-Mail: sarah.kohler@kit.edu \\ 2 Department of Media and Communications, University of Klagenfurt, 9020 Klagenfurt, Austria; \\ E-Mail: isabell.koinig@aau.at \\ * Corresponding author
}

Submitted: 31 January 2020 | Accepted: 26 May 2020 | Published: 26 June 2020

\begin{abstract}
In a period characterized by vaccine hesitancy and even vaccine refusal, the way online information on vaccination is presented might affect the recipients' opinions and attitudes. While research has focused more on vaccinations against measles or influenza, and described how the framing approach can be applied to vaccination, this is not the case with tick-borne encephalitis, a potentially fatal infection induced by tick bites. This study takes one step back and seeks to investigate whether health and scientific frames in online communication are even recognized by the public. Moreover, the influence of selected health- and vaccine-related constructs on the recognition of frames is examined. Study results indicate that health frames are the most easily identified and that their use might be a fruitful strategy when raising awareness of health topics such as vaccination.
\end{abstract}

\section{Keywords}

framing; health communication; science communication; tick-borne encephalitis; vaccination

\section{Issue}

This article is part of the issue "Health and Science Controversies in the Digital World: News, Mis/Disinformation and Public Engagement" edited by An Nguyen (Bournemouth University, UK) and Daniel Catalan (University Carlos III of Madrid, Spain).

(C) 2020 by the authors; licensee Cogitatio (Lisbon, Portugal). This article is licensed under a Creative Commons Attribution 4.0 International License (CC BY).

\section{Introduction: Vaccination and Framing in Health Communication}

In recent years, news coverage and public debates have shown that people discuss vaccination and even refuse to vaccinate themselves or their children (Schoeppe et al., 2017, p. 654). Many studies have already investigated the reasons why people do, and do not, get vaccinated (e.g., Askelson et al., 2010; Berman, Orenstein, Hinman, \& Gazmararian, 2010). Online media has been found to have a particularly strong impact on people's perceptions of vaccination (Betsch, 2011; Betsch, Böhm, Korn, \& Holtmann, 2017; Nyhan \& Reifler, 2015). As people increasingly consult the Internet for health-related information (Din, McDaniels-Davidson, Nodora, \& Madanat, 2019), vaccination is no exception to this trend (Betsch, Renkewitz, Betsch, \& Ulshöfer, 2010; Kessler \& Zillich, 2018) and it is likely that such Internet research will likely influence people's attitudes towards vaccination.

Hence, online messages and the way websites present arguments are a key factor in shaping individual attitudes towards vaccination. In the following, we define such arguments as frames, which refer to "organizing principles that are socially shared and persistent over time, that work symbolically to meaningfully structure the social world" (Reese, 2010, p. 11). Frames are best conceptualized as "interpretation packages" (Gamson \& 
Modigliani, 1989, p. 1) to present a specific issue. As such, they help structure arguments and ideas (Reese, 2010). Moreover, to frame means "to select some aspects of perceived reality and make them more salient in a communicating text" (Entman, 1993, p. 52). Research has already combined framing and vaccination issues but has been mostly focused on selected aspects, single frames, or one particular research perspective (Bigman, Cappella, \& Hornik, 2010; Kim, Pjesivac, \& Jin, 2019; McRee, Reiter, Chantala, \& Brewer, 2010; Nan, Daily, Richards, \& Holt, 2019). Yet, the identification of frames as employed in health communication messages is crucial, given that the way messages are framed is likely to reflect selected health goals (Hallahan, 2015), and is likely to affect people's message perceptions subconsciously (Coleman, 2010). In this context, frames in health-related messages, such as online websites on vaccination, are expected to have positive effects on users.

\section{Antecedents to Frame Recognition and Frame Perception}

Apart from frames in messages, previous research has determined that health-related variables moderate responses to health messages regarding drug advertisements (e.g., Koinig, Diehl, \& Mueller, 2017; Lee, Whitehill King, \& Reid, 2015) We also presume individuals' attitudes to be subject to a variety of health- or vaccinerelated variables (World Health Organization [WHO], 2014) just like vaccination hesitancy, which is influenced by "complacency, convenience and confidence" (WHO, 2014, p. 11).

First, confidence in vaccination is crucial for behavioral beliefs associated with vaccinations, and as such, also determines individual attitudes towards vaccinations (Shapiro et al., 2018). It includes trust "in the effectiveness and safety of vaccines, the system that delivers them, including the reliability and competence of the health services and health professionals, and the motivations of policy-makers who decide on the need of vaccines" (MacDonald, 2015, p. 2). If confidence is high, individuals regard vaccinations positively (Askelson et al., 2010). Another construct which is highly correlated with confidence in vaccination and one of the most important assets in health communication (Zagaria, 2004) is health literacy. Health literacy refers to routine practices and activities utilized by individuals as part of their illness control mechanisms (Marks, Allegrante, \& Lorig, 2005). As such, health literacy "represents the cognitive and social skills which determine the motivation and ability of individuals to gain access to, understand and use information in ways which promote and maintain good health" (Nutbeam, 1998, p. 10). Additionally, collective responsibility alludes to the fact that individuals presume that through collective action, a potential health problem can be solved (Betsch et al., 2018). This suggests that individuals might decide to get vaccinated because they see the benefit for their communities, rather than their own benefit (Betsch et al., 2017). This concept is highly relevant to diseases, such as influenza and measles, which are spread widely among the unvaccinated. In this context, health consciousness might be also relevant, which is grounded in individual differences and people's inclination towards the subject matter (Dutta, Bodie, \& Basu, 2008), moderating health perception (Moorman \& Matulich, 1993). Individuals expressing high levels of health consciousness are expected to be more prone to, e.g., search for information conducive to their wellbeing or engage in health-enhancing behaviors; as such, they are also presumed to be more interested in and willing to vaccinate themselves. This leads to another set of behavioral variables which influence the perception of information as well. Health information-seeking behavior is linked to positive health attitudes, an urge to search for further information as well as a need to consult (with) different sources (Dutta-Bergman, 2004). The sources individuals consult can be either distinct media channels and/or interpersonal sources (Niederdeppe et al., 2007). As such, it is also predicted that this behavior will positively shape individuals' perceptions of health information. Besides, calculation refers to "the need for extensive elaboration and information searching" (Betsch et al., 2018, p. 3). Individuals scoring high in this dimension have been found to proactively engage in information-seeking behavior; because of their high knowledge of the individual health issues, they are expected to favor vaccination (Brewer, Cuite, Herrington, \& Weinstein, 2007) and are known to behave rationally (Wiseman \& Watt, 2004).

To sum up, we assume that both individual predispositions (confidence in vaccination, health literacy, collective responsibility, health consciousness), as well as individual behavior (health information seeking behavior, calculation), have an impact on how messages are perceived. Yet, research has predominantly focused on the perception of messages and frames instead of asking if such frames are even recognized. It is plausible that the behavioral antecedents might influence the recognition of frames, while the predispositions might influence the perception of frames.

\section{The Relevance of Vaccination against Tick-Borne Encephalitis in Austria}

While a plethora of vaccination studies have predominantly focused on vaccinations against human papillomavirus (HPV), measles, mumps, and rubella (MMR), or influenza, little research has been conducted on tickborne encephalitis (TBE). TBE is a potentially fatal infectious disease transmitted by ticks. It occurs in most forest belted areas of Europe, including Austria (Zavadska et al., 2018), and if untreated can endanger individuals' health and life. In contrast to HPV, MMR, and influenza, TBE is only transmitted by tick bites and not by humans. Therefore, the vaccination for TBE is different, because it prevents only a single person from the disease, while 
other diseases affect the entire population directly. Yet, TBE is still linked with costs for both individuals and society (Smit, 2012, p. 6301), given its long-term neurological sequelae which require long-term care and cause a loss of productivity and premature retirement (WHO, 2011, p. 254). From 1999-2000, Austria ran a large immunization campaign against TBE, which was estimated to have saved the national health care system an equivalent of $\$ 80$ million (WHO, 2011, p. 254). Furthermore, climate change has influenced the spread of ticks due to the milder and shorter winters and the early arrival of spring (Lindgren \& Gustafson, 2001), which has resulted in an increased number of incidents of TBE (Zavadska et al., 2018), which are expected to lead to higher healthrelated costs.

Amongst central European countries, Austria has been especially affected by an increasing number of tick bites in recent years with the number of hospitalizations increasing from 2015 onwards (Allianz, 2018). As of 2014, only half of the Austrian population had tried to prevent TBE infections by getting vaccinated (Österreichischer Rundfunk, 2015). The following year, protective measures increased, with $65 \%$ of respondents claiming to have been vaccinated against TBE in 2015 (Statista, 2019). Given that infections and deaths by TBE are on the rise in Austria, both the government and health care or pharmaceutical marketers have been prompted to raise awareness of the need for TBE-vaccination. While the most effective protection against tick bites are vaccinations or personal protection measures, such as long clothes or tick-repellent sprays (Driver, 2011), both measures will not be sufficient if people are not aware of the risks associated with TBE. Yet to date, most papers on the subject of TBE have rather focused on the medical or natural scientific aspects of TBE, addressing issues such as the spread of ticks (Lindgren \& Gustafson, 2001) instead of informing the public of the dangers TBE poses to society and social well-being. However, informing the public about ticks and TBE is deemed necessary and insights from message framing might help educate the public on TBE. For instance, websites hosted by pharmaceutical companies, such as Pfizer and those partly supported by governmental departments, address the risks associated with tick bites. Such cooperation between government and pharmaceutical companies qualify as a form of public health communication (Bonfadelli \& Friemel, 2020), which also applies to the website on TBE which relies on specific frames to communicate their messages.

\section{Health Frames and Scientific Frames in TBE Communication}

Vaccination against TBE tackles health communication, as well as science communication since websites on TBE include information which is directly meant to promote health-related behaviors that are, in most instances, based on scientific evidence (e.g., Cooper, Lee, Goldcare, $\&$ Sanders, 2012). As summarized above, research on framing and vaccination has rather focused on single frames or single perspectives. We would like to enhance the understanding of frames by suggesting a differentiation between health frames, which are rather emotional and scientific frames, which are rather based on neutral information.

For the first category we have chosen character frames (e.g., Dan \& Coleman, 2014) which are increasingly used in the areas of health communication (e.g., Koinig et al., 2017) and science communication (e.g., Kessler, Reifegerste, \& Guenther, 2016). Character frames allude to affective frames that are able to evoke emotions and reactions in recipients (Grabe \& Bucy, 2009). According to Dan and Coleman (2014) and Dan (2018), four frames can be distinguished: victim frames (i.e., a person affected by the disease, who is portrayed as weak; negative disease symptoms are emphasized), survivor frames (i.e., a healthy individual or hero-like figure, who has overcome the disease; positive attributes are stressed), carrier frames (i.e., an extremely negative portrayal of the health condition, caused by deviant behavior), and normal frames, in which people are presented as both ordinary and in normal surroundings, and in a state where the disease is not perceived as a burden. These considerations apply to communication of TBE, too. We assume that scientific frames on TBE are different from health frames. While health frames are affective and likely to evoke emotional responses in recipients by focusing on individual aspects such as well-being, scientific frames are neutral and focus on scientific evidence based on robust ecological data and present information in a factual manner.

For the second category of scientific frames and following the example of Ruhrmann, Guenther, and Kessler (2015), variables related to scientific evidence such as scientific (un)certainty and progress will receive consideration (Cooper et al., 2012). Based on Entman (1993, p. 52), the four frames-problem definition, causal interpretation, moral evaluation, and treatment recommendation-are broadly applicable to neutral and factual scientific frames. Problem definition concerns identifying both relevant actors and topics involved in the discussion at hand (Bowe, Oshita, Terracina-Harman, \& Chao, 2012) and it is commonly linked to scientific (un)certainty. Causal attribution involves uncovering the reasons and causes behind certain problems (Bowe et al., 2012). Moral evaluation includes a rating of the findings presented, and, as such, is often based on negative or positive judgements (Entman, Matthes, \& Pellicano, 2009). Finally, in the process of treatment recommendation, solutions to the previously identified problem are formulated, which are often presented in a forward-looking, predicting manner (Matthes \& Kohring, 2008).

We presume that, on the one hand, frames which we describe as health frames are affective in that they emphasize personal and emotional aspects; furthermore, they become manifest in character frames. This category is characterized by a significant research gap (Guenther, 
Gaertner, \& Zeitz, 2020). On the other hand, we conceptualize neutral and factual frames as scientific frames, as information is usually based on scientific reasoning and facts. We have chosen the terms 'health frames' and 'scientific frames' to emphasize their respective character. Of course, 'scientific frames' were used in health communication as well as health frames were used in science communication, too. Hence, the present study extends previous research, in which calls for a more comprehensive and categorically broader conceptualization of framing in health communication have been made (Guenther et al., 2020). As we have outlined above, behavioral variables, as well as individuals' predisposition, might influence the perception of frames. Yet, we would like to take a step back and instead investigate whether health frames and scientific frames are even recognized and whether their detection may be influenced by respondents' attitudes and behaviors. We employ a joint approach since we assume that people do not recognize both frame types in a similar manner. Therefore, our two research questions are:

RQ1: Are health or scientific frames recognized more frequently?

RQ2: Is the recognition of health and scientific frames influenced by selected health- and vaccine-related antecedents?

\section{Method and Materials}

\subsection{Study Design}

The goal of our study is to determine whether scientific frames or health frames are more frequently identified by the Austrian public and which antecedents influence the frame recognition of the study participants. We conducted an online survey and showed participants texts from an Austrian website on TBE. The texts contained five different frames. After reading the texts, participants were asked several questions as to the antecedents and if they recognized the frames.

We carefully selected our text material for the online questionnaire. First, we used eye-tracking to identify texts which were read by common users of the Austrian website on TBE. Second, we conducted a content analysis of those messages in order to identify both the scientific frames and health frames as featured in the text. Finally, these texts and identified frames were used in the online survey. Figure 1 outlines our study procedure.

\subsection{Selection and Validation of Text Material}

\subsubsection{Eye-Tracking}

We analyzed an Austrian pro-vaccination website (www.zecken.at). This website is hosted by a pharmaceutical company, but the overall initiative is a joint endeavor with the Austrian health care ministry. We used

\section{Study design}

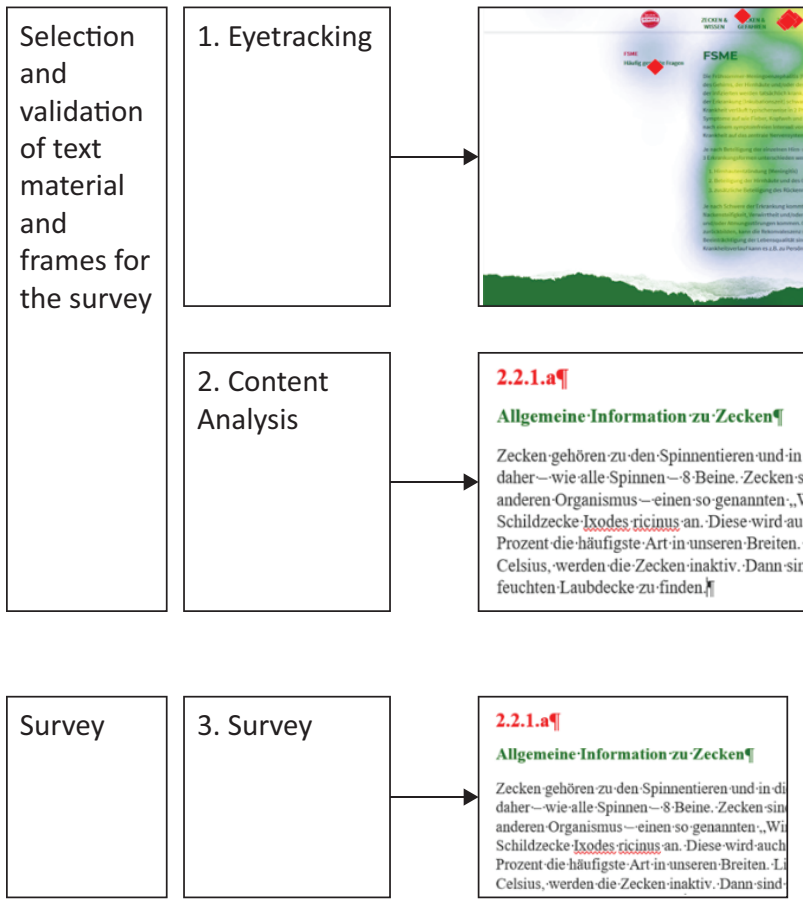

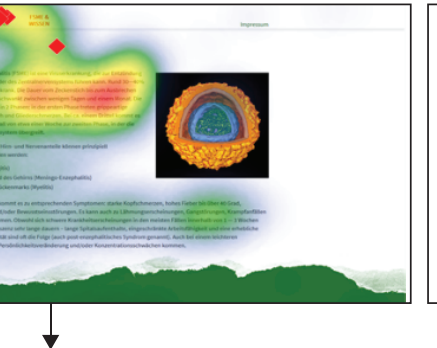

-in. die-Untergruppe-der-Milben. Die-erwachsene-Zecke-hat en. sind,.Parasiten", d.h. sie.brauchen -zum. Oberleben ein

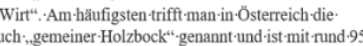
en. Liegen die-Temperaturen -unter funf bis sieben-Grad
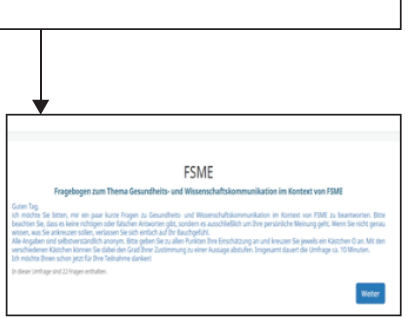

Heatmaps and scanpaths were used to determine which texts on the website www.zecken.at draw the participants' attention.

Texts and identified frames were
included in the survey. Participants
were asked to indicate which frame
chatacteristics they had perceived
in the text.

Figure 1. Study design and procedure. Source: Authors. 
an eye-tracking study to identify those texts on the website that drew the reader's attention. We asked participants $(n=15)$ to gather information on TBE, giving them up to 10 minutes to search the website. Additionally, we controlled the experiment by asking the participants to gather information on bee-friendly gardening. Using both examples, we were able to analyze if there were significant differences between the eye movements, which was not the case. We used scan paths and heatmaps. If an area (and text) did not draw any (zero) attention in terms of looking at it or reading it (scan paths show reading patterns), the specific text was neither included in the followed-up content analysis nor the survey.

\subsubsection{Content Analysis}

The content analysis aimed to uncover which (health and scientific) frames the texts contained. First, we used 17 frames based on a literature review and derived definitions for each frame type including examples in a codebook. After pre-testing the codebook and some minor adjustments, a research group consisting of five students analyzed the texts. In total, five frames were identified (Table 1): two health frames, the carrier frame-which inquires whether the text addressed the negative health consequences associated with tick bites-and the victim frame, which particularly focused on the negative effects for the individual. Additionally, there were three scientific frames: problem definition - which highlighted the sources for the health issue and its public relevance-causal attribution-which listed reasons as to why a health problem is increasing in relevance-and treatment recommendation. The texts themselves, as well as the frames identified, were then employed as stimulus material in the respective question categories of the main study.

\subsection{Online Survey}

\subsubsection{Study Description}

Subjects for the study were recruited via asking students to send out the link of the online survey to friends and family members. This non-probability sampling method leads to a non-student convenience pool. While this sample does not allow us to draw conclusions for the overall Austrian population, it does, however, ensure a higher degree of heterogeneity than a sample based solely on stu- dents (Leiner, 2016, p. 216). Further, as we seek to investigate whether frames are recognized in general, we are still able to derive viable conclusions regarding potential differences in frame recognition among a more diverse sample. In total, 271 subjects participated in the structured questionnaire. Respondents were between 18 and 80 years old $(M=36.3, S D=14.48)$. The largest part of the sample was made up of women ( $f=65.7 \% ; m=34.3 \%$ ).

After determining the antecedents regarding individuals' predispositions and behavioral aspects, the questionnaire ascertained respondents' familiarity with the term TBE. Regardless of their answer, individuals were presented with a definition in order to ensure an equal state of knowledge before exposing them to the stimulus texts. After reading through the text, questions related to message comprehensibility as well as the included health and scientific frames were posed. The questionnaire concluded with demographic questions.

\subsubsection{Measurements}

The answers to each question were reported on a 7-point Likert scale ranging from (1) 'I do not agree at all' to (7) 'I fully agree.' Factor analyses revealed the items of the all multi-item variables to load on one single factor and to have acceptable Cronbach $\alpha$ values, thus they were combined for analysis:

- 'Confidence in vaccination' was measured with the $5 \mathrm{C}$ psychological antecedents of vaccination scale (Betsch et al., 2018), utilizing three items (KMO =.500, $\mathrm{p}=.000 ; \alpha=.904)$.

- 'Health literacy' was determined by one single item as derived from Lee, Hwang, Hawkins, and Pingree (2008).

- 'Collective responsibility' was derived from the same scale (Betsch et al., 2018) and was measured by two items (KMO =.500, $\mathrm{p}=.000 ; \alpha=.721)$.

- 'Health consciousness' (Dutta et al., 2008) was measured via one question based on Gould (1988, 1990) and Dutta-Bergman (2004).

- 'Health information seeking behavior' was established through two questions adapted from Maibach, Weber, Massett, Hancock, and Price (2006) and Kapferer and Laurent (1985; $\mathrm{KMO}=.500, \mathrm{p}=.000 ; \alpha=.755)$.

- 'Calculation' was also based on the 5C psychological antecedents of vaccinations scale (Betsch

Table 1. Frame category and frame type.

\begin{tabular}{lll}
\hline Frame category & Frame type & Based on \\
\hline Health frames & Carrier frame & Dan and Coleman (2014); Dan (2018) \\
& Victim frame & \\
Scientific frames & Problem definition & Entman (1993) \\
& Causal attribution \\
& Treatment recommendation & \\
\hline
\end{tabular}


et al., 2018) and was determined by three questions (KMO $=.680, \mathrm{p}=.000 ; \alpha=.796)$.

In addition, we set out to determine the degree to which respondents were able to identify the previously highlighted frames. Each frame was operationalized with two statements to which the respondents were asked to answer on a 7-point Likert scale ranging from (1) 'I do not agree at all' to (7) 'I fully agree' (Table A1 in the Supplementary File). The carrier frame inquired whether the text addressed the negative (health) consequences associated with tick bites ( 2 questions; $\mathrm{KMO}=.500$, $\mathrm{p}=.000 ; \alpha=.759)$, while the victim frame particularly focused on the negative effects for the individual ( 2 questions; $\mathrm{KMO}=.500, \mathrm{p}=.000 ; \alpha=.717)$. Problem definition (i.e., highlighting the sources for the issue and its public relevance) was measured via two questions (KMO $=.500, \mathrm{p}=.000 ; \alpha=.759)$. Likewise, causal attribution-listing the reasons why a (health) problem is increasing in relevance-was measured via 2 questions (KMO $=.500, \mathrm{p}=.000 ; \alpha=.734)$, while treatment recommendation was concerned with the availability of solutions to the (health) problem (1 question). Items for the two health frame categories were based on Dan (2018), while items for the three scientific frames were based on Entman (1993).

\section{Results}

\subsection{Health and Scientific Frames}

The first research question was interested in uncovering whether health frames or scientific frames were recognized more frequently in the text passages used (Table 2). Generally, it can be noted that out of all frames featured in the text, the two health frames-namely the carrier frame $(M=6.072, S D=1.231)$ and the victim frame $(M=6.055, S D=1.181)$ - were detected more often by respondents. Subjects were further able to make out the scientific frames problem definition ( $M=5.516$, $\mathrm{SD}=1.286)$ as well as determine TBE's causal attribution ( $M=5.479, S D=1.236)$; to a slightly lesser extent, they identified the recommended treatment $(M=4.48$, SD $=1.907$ ).

When looking at the frame categories in more detail and determining if there are significant differences between the recognition of health frames and scien- tific frames, the carrier frame was significantly more frequently identified than the three scientific frames: problem definition $(T=8.455, p=.000)$, causal attribution ( $T=8.179, p=.000)$, and treatment recommendation ( $T=12.468, p=.000)$. The second health frame, namely the victim frame, was also more easily discerned than the scientific frames problem definition $(T=8.727$, $p=.000)$, causal attribution $(T=8.274, p=.000)$, and treatment recommendation ( $T=12.576, p=.000)$. No significant differences between the two health frames were reported $(T=.453, p=.651)$. This means that both health frames function similarly, yet there are differences between health frames and scientific frames. Overall, the results point in the same direction and suggest that health frames are significantly more frequently identified than scientific frames $(T=15.927, p=.000)$.

\subsection{Antecedents and Their Influence on the Recognition of Health and Scientific Frames}

The second research question investigated which antecedents influenced the recognition of health frames and scientific frames. As research on framing usually tries to examine the perception of frames, this study focuses on a previous step, i.e., figuring out if antecedents might already influence frame recognition. We distinguish between antecedents which are related to individuals' attitudes (confidence in vaccination, health literacy, health consciousness, collective responsibility) and antecedents which include behavioral aspects (health informationseeking behavior, calculation). We calculated two multiple linear regressions and added the antecedents as predictors for health frame recognition or scientific frame recognition. Age and gender were included as controlling variables which allowed us to analyze whether the recognition of scientific frames or health frames is dependent on individuals' attitudes or behavioral aspects. The results of the regression analysis are presented in Tables 3 and 4 . In the Supplementary File, more details on the influence of the previously identified variables on each of the two health frames and three scientific frames can be found (see Tables A2 to A6).

For health frames, the model fit turned out to be significant and accounted for almost $18 \%$ of the variance $\left(R^{2}=.175, F(8,270)=6.928, p=.000\right.$; Table 3$)$. The standardized regression weights beta show which of the antecedents have a higher impact on the recognition

Table 2. Mean and standard deviation of health and scientific frames.

\begin{tabular}{llll}
\hline Frame category & Frame & M & SD \\
\hline Health frames & Carrier frame & 6.072 & 1.231 \\
& Victim frame & 6.055 & 1.181 \\
Scientific frames & Problem definition & 5.516 & 1.286 \\
& Causal attribution & 5.479 & 1.236 \\
& Treatment recommendation & 4.480 & 1.907 \\
\hline
\end{tabular}

Note: Model fit of health frames vs. scientific frames: $T=15.927, p=.000$. 
Table 3. Regression results using recognition of health frames as a criterion.

\begin{tabular}{llll}
\hline Predictors & $\mathrm{B}$ & beta & $\mathrm{p}$ \\
\hline (Intercept) & 2.915 & & .000 \\
Confidence in vaccination & .052 & .080 & .288 \\
Health literacy & .089 & .099 & .103 \\
Health consciousness & .122 & .137 & .036 \\
Collective responsibility & .138 & .200 & .006 \\
Health information seeking behavior & .102 & .122 & .058 \\
Calculation & .100 & .138 & .030 \\
Age & .000 & .013 & .221 \\
Gender & .020 & .008 & .142 \\
\hline
\end{tabular}

Note: 'B' represents unstandardized regression weights, 'beta' indicates the standard regression weights, and ' $\mathrm{p}$ ' refers to significance.

of health frames. Collective responsibility (beta $=.200$, $\mathrm{p}=.006$ ) and health consciousness (beta $=.137, \mathrm{p}=.036$ ) as individuals' attitudes influence the recognition of health frames more than both behavioral variables, calculation (beta $=.138, p=.030$ ) and health information seeking behavior (beta $=.122, p=.058$ ). The latter is, unfortunately, just over the threshold of significance. The other predictors are not significant and therefore do not contribute to the recognition of health frames.

In the case of scientific frames, the model fit was also significant $\left(R^{2}=.074, F(8,270)=2.610, p=.009 ;\right.$ Table 4). Yet, only health information seeking behavior was found to be a useful predictor (beta $=.163, p=.017$ ), while the impact of all other antecedents was not significant. The model explained only $7 \%$ of the variance. Therefore, the variables which have a stronger effect on the recognition of scientific frames are obviously missing in this study.

The results of the regression showed that given the quite low explained variance in both models, additional analysis is required. Nevertheless, analyzing these results we note the positive relationship between health consciousness, collective responsibility, calculation, and health frames. However, only health-seeking behavior can influence the recognition of scientific frames.

\section{Discussion}

Our study was interested in uncovering specific healthrelated antecedents as formed in response to scientific (neutral) frames and health (affective) frames in TBE communication amongst the Austrian population-an area that has received very limited academic attention to date. Rather than other framing studies on vaccination, we wanted to scrutinize whether frames are even recognized before being perceived or judged. We conducted an online survey and carefully selected the stimulus material using eye-tracking and content analysis. We focused on the effects of frame recognition and tried to determine whether the recognition of frames differed, depending on whether the frame was classified as a health (character) frame or scientific (neutral) frame. Therefore, we used a convenience sample which does not allow us to draw conclusions for the Austrian population in general yet shows differences in the recognition of frames (also see limitations in Section 8).

While previous research has been able to confirm the co-existence of multiple frames (Matthes \& Kohring, 2008), the present study moved beyond a pure content analysis, indicating that frames might be detected to varying degrees. Overall results suggest that health frames are recognized more often than scientific frames. One potential explanation for this tendency is that affective (and thus, emotional) frames are able to elevate respondents' personal involvement by heightening the perception of personal relevance and risk associated with tick bites and TBE. This is in line with previous research indicating that similarity can be a useful tool to increase message effectiveness (Ahn, Fox, \&

Table 4. Regression results using recognition of scientific frames as a criterion.

\begin{tabular}{lcccc}
\hline Predictors & $\mathrm{B}$ & beta & $\mathrm{p}$ & $\mathrm{R}^{2}$ \\
\hline (Intercept) & 3.712 & & .009 & .074 \\
Confidence in vaccination & .049 & .095 & .237 & .937 \\
Health literacy & -.004 & -.005 & .289 \\
Health consciousness & .052 & .073 & .825 \\
Collective responsibility & -.009 & -.017 & .017 \\
Health information seeking behavior & .108 & .163 & .110 \\
Calculation & .062 & .107 & .104 \\
Age & .001 & .098 & .999 \\
Gender & .000 & .000 &
\end{tabular}

Note: ' $\mathrm{B}$ ' represents unstandardized regression weights, 'beta' indicates the standard regression weights, and ' $\mathrm{p}$ ' refers to significance. 
Hahm, 2014), whereby the perceived relevance of the message can trigger individuals to identify with message content (So \& Nabi, 2013). The same was found to hold true for messages corresponding to individual preferences (Lobinger, 2012; Stark, Edmonds, \& Quinn, 2007). Hence, by increasing identification and personal relevance-through the inclusion of thematic and affective frames or tailoring - negative message effects can be mitigated (Kreuter, Strecher, \& Glassman, 1999; Kreuter \& Wray, 2003). This is an interesting finding given that informational content devoid of any emotional element has dominated the present-day health communication debate. It seems that providing consumers information alone appears will not suffice, on the contrary, health information should involve consumers emotionally. This then suggests that when considering how to make messages appealing, the best option is to combine informative and emotional elements. For this reason, the inclusion of health and character frames could prove to be a fruitful strategy for health messages.

Besides identifying frames via two different methodological approaches and thus ensuring the robustness of results (David, Atun, Fille, \& Monterola, 2011), through our study we were also able to demonstrate that selected health- and vaccine-related constructs influenced the recognition of both health frames and scientific frames. For instance, previous studies have determined that both health consciousness and health information seeking behavior are viable constructs to predict health outcomes (Shim, Kelly, \& Hornik, 2006; van der Molen, 1999). In terms of message comprehension, health information seeking behavior has been positively linked to information engagement and information apprehension (Strekalova, 2014). In our study, health informationseeking behavior was only positively and significantly linked to the recognition of scientific frames. Hence, it appears that if individuals are actively seeking health information, they are looking for more neutral information and therefore recognize scientific frames more easily. When it comes to the health frames, health consciousness, collective responsibility, and calculation were predictors to explain the recognition of the two health frames. Health information seeking behavior was not significant. Health consciousness refers to individuals who are more prone to and engage in health-enhancing behaviors, such as the willingness to be vaccinated. The emotional aspects of the health frames seem to be in line with the need to take care of oneself. Presupposing a communal orientation, collective responsibility was also found to influence individuals' health frame recognition. This might be conditioned by the fact that both frame types, the carrier frame and the victim frame, presuppose some group embeddedness, whereby the contribution of the individual to collective well-being is stressed. Still, it is quite interesting that collective responsibility influences the recognition of health frames since TBE is a disease which is not spread by human beings. An explanation could be that people feel responsi- ble for others in their immediate environment, e.g., parents who take care of their children and think about getting them vaccinated. In this case, the health frames fit quite well as the expectation of a possibly fatal course of the disease might trigger negative emotions in recipients. Yet, in this case, the relationship between cause and effect needs to be examined more thoroughly. The calculation is closely linked to the health-related construct of health consciousness, and thus individuals are pre-supposed to detect health frames more readily due to the high investment of cognitive resources. Although we distinguished between attitudes and behavioral aspects, none was more prone to affect frame recognition. As the explained variance of the second regression was even quite low, it rather suggests thinking about other variables which might affect the recognition of scientific frames.

\section{Limitations and Suggestions for Future Research}

According to Borah's (2011) recent literature review, framing can be either sociological or psychological in nature. In the case of sociological frame analysis (Entman, 1993), the presentation of arguments in texts is scrutinized in detail, while in the case of psychological frame analysis (Tversky \& Kahneman, 1981), individual perceptions of the information retrieved are subject to analysis. The present study tried to shed light on those concepts by asking if antecedents might already influence the recognition of frames. While our explorative study was innovative in examining a research area (vaccinations against TBE), which is not yet at the center of scientific attention, there are several limitations to our study. First, our quantitative survey was based on a small convenience sample. We found effects, yet we cannot draw representative conclusions for the Austrian population. If future research intends to elucidate how the Austrian population recognizes frames, it should be replicated with a larger and more diverse sample. Likewise, as the present study only focused on texts addressing the risks associated with TBE, future studies might want to explore different content (e.g., videos or social media content). For this purpose, conducting an integrative frame analysis as proposed by Dan (2018) might be worthwhile. Additionally, the differentiation of whether content drew respondents' attention or did not draw their attention might be an interesting aspect for future research. Furthermore, this study design could not answer how the highlighted frames are actually perceived by the public. We suggest turning to qualitative methods (e.g., focus groups) to examine how health frames and scientific frames are perceived. Finally, we are aware that we are not able to determine if we have another causal relationship between the antecedents and frame recognition. It is also possible that the detection of the frames influences other factors, e.g., collective responsibility towards family members. In this case, an experimental design is needed, which can scrutinize if those 
antecedents are predictors or criteria towards the recognition of frames.

\section{Acknowledgments}

We would like to thank the editors and the reviewers for their recommendations as well as the study courses of Klagenfurt and Karlsruhe for their help with conducting this study.

\section{Conflict of Interests}

The authors declare no conflict of interests.

\section{Supplementary Material}

Supplementary material for this article is available online in the format provided by the author (unedited).

\section{References}

Ahn, S. J., Fox, J., \& Hahm, J. M. (2014). Using virtual doppelgängers to increase personal relevance of health risk communication. In T. Bickmore, S. Marsella, \& C. Sidner (Eds.), Intelligent virtual agents (IVA 2014) (pp. 1-12). Cham: Springer.

Allianz. (2018). Kann man sich gegen Zeckenbisse versichern? [Does insurance cover tick bites?]. Allianz Blog. Retrieved from https://blog.allianz.at/zeckenbisseversichern

Askelson, N. M., Campo, S., Lowe, J. B., Smith, S., Dennis, L. K., \& Andsager, J. (2010). Using the theory of planned behavior to predict mothers' intentions to vaccinate their daughters against HPV. The Journal of School Nursing: The Official Publication of the National Association of School Nurses, 26(3), 194-202. https://doi.org/10.1177/1059840510366022

Berman, P. P., Orenstein, W. A., Hinman, A. R., \& Gazmararian, J. (2010). Stakeholder attitudes toward influenza vaccination policy in the United States. Health Promotion Practice, 11(6), 807-816. https:// doi.org/10.1177/1524839909331552

Betsch, C. (2011). Innovations in communication: The internet and the psychology of vaccination decisions. Eurosurveillance, 16, 1-6.

Betsch, C., Böhm, R., Korn, L., \& Holtmann, C. (2017). On the benefits of explaining herd immunity in vaccine advocacy. Nature Human Behaviour, 1(56), 1-6. https://doi.org/10.1038/s41562-017-0056

Betsch, C., Renkewitz, F., Betsch, T., \& Ulshöfer, C. (2010). The influence of vaccine-critical websites on perceiving vaccination risks. Journal of Health Psychology, 15(3), 446-455. https://doi.org/10.1177/ 1359105309353647

Betsch, C., Schmid, P., Heinemeier, D., Korn, L., Holtmann, C., \& Böhm, R. (2018). Beyond confidence: Development of a measure assessing the $5 \mathrm{C}$ psychological antecedents of vaccination. PLOS ONE,
13(12), e0208601. https://doi.org/10.1371/journal. pone.0208601

Bigman, C. A., Cappella, J. N., \& Hornik, R. C. (2010). Effective or ineffective: Attribute framing and the human papillomavirus (HPV) vaccine. Patient Education and Counseling, 81(Suppl. 1), 70-76. https://doi.org/ 10.1016/j.pec.2010.08.014

Bonfadelli, H., \& Friemel, T. N. (2020). Kommunikationskampagnen im Gesundheitsbereich: Grundlagen und Anwendungen [Health communication campaigns: Basics and applications]. Cologne: Herbert von Halem.

Borah, P. (2011). Seeking more information and conversations: Influence on competitive frames and motivated processing. Communication Research, 38(3), 303-325. https://doi.org/10.1177/ 0093650210376190

Bowe, B. J., Oshita, T., Terracina-Harman, C., \& Chao, W. C. (2012). Framing of climate change in newspaper coverage of the East Anglia e-mail scandal. Public Understanding of Science, 23(2), 157-169. https:// doi.org/10.1177/0963662512449949

Brewer, N. T., Cuite, C. L., Herrington, J. E., \& Weinstein, N. D. (2007). Risk compensation and vaccination: Can getting vaccinated cause people to engage in risky behaviors? Annals in Behavioral Medicine, 34(1), 95-99.

Coleman, R. (2010). Framing the pictures in our heads. Exploring the framing and agenda-setting effects of visual Images. In P. D’Angelo \& J. A. Kuypers (Eds.), Doing news framing analysis: Empirical and theoretical perspectives (pp. 233-261). New York, NY: Routledge.

Cooper, B. E. J., Lee, W. E., Goldcare, B. M., \& Sanders, T. A. B. (2012). The quality of the evidence for dietary advice given in UK national newspapers. Public Understanding of Science, 21(6), 664-673. https:// doi.org/10.1177/0963662511401782

Dan, V. (2018). Integrative frame analysis: Framing health through words and visuals. London and New York, NY: Routledge.

Dan, V., \& Coleman, R. (2014). Coming down from the Ivory Tower: Visual frames of HIV/AIDS in the academic literature and broader society. Paper presented at the International Communication Association Conference 2014, Seattle, WA, USA.

David, C. C., Atun, J. M., Fille, E., \& Monterola, C. (2011). Finding frames: Comparing two methods of frame analysis. Communication Methods and Measures, 5(4), 329-351. https://doi.org/10.1080/ 19312458.2011.624873

Din, H. N., McDaniels-Davidson, C., Nodora, J., \& Madanat, H. (2019). Profiles of a health informationseeking population and the current digital divide: Cross-sectional analysis of the 2015-2016 California health interview survey. Journal of Medical Internet Research, 21(5), e11931. https://doi.org/ 10.2196/11931 
Driver, C. (2011). Tick-borne encephalitis. Practice Nurse, 41(6), 13-17.

Dutta, M. J., Bodie, G. D., \& Basu, A. (2008). Health disparity and the racial divide among the nation's youth: Internet as a site for change? In A. Everett (Ed.), Learning race and ethnicity: Youth and digital media ( $\mathrm{pp}$. 175-198). Cambridge, MA: MIT Press.

Dutta-Bergman, M. (2004). Health attitudes, health cognitions and health behaviors among Internet health information seekers: Population-based survey. Journal of Medical Internet Research, 6(2), e15. https:// doi.org/10.2196/jmir.6.2.e15

Entman, R. M. (1993). Framing: Toward clarification of a fractured paradigm. Journal of Communication, 43(4), 51-58. https://doi.org/10.1111/j.1460-2466. 1993.tb01304.x

Entman, R. M., Matthes, J., \& Pellicano, L. (2009). Framing politics in the news: Nature, sources, and effects. In K. Wahl-Jorgensen \& T. Hanitzsch (Eds.), Handbook of journalism studies (pp. 175-190). Mahwah, NJ: Lawrence Erlbaum.

Gamson, W. A., \& Modigliani, A. (1989). Media discourse and public opinion on nuclear power: A constructionist approach. American Journal of Sociology, 95(1), 1-37.

Gould, S. J. (1988). Consumer attitudes toward health and health care: A differential perspective. Journal of Consumer Affairs, 22(1), 96-118.

Gould, S. J. (1990). Health consciousness and health behavior: The application of a new health consciousness scale. American Journal of Preventive Medicine, 6(4), 228-237.

Grabe, M. E., \& Bucy, E. P. (2009). Image bite politics: News and the visual framing of elections. Oxford: Oxford University Press.

Guenther, L., Gaertner, M., \& Zeitz, J. (2020). Framing as a concept for health communication: A systematic review. Health Communication. Advance online publication. https://doi.org/10.1080/10410236. 2020.1723048

Hallahan, K. (2015). Strategic Framing. In W. Donsbach (Ed.), The concise encyclopedia of communication (p. 600). Malden, MA: Wiley.

Kapferer, J.-N., \& Laurent, G. (1985). Consumer involvement profiles: A new practical approach to consumer involvement. Journal of Advertising Research, 25(6), 48-56.

Kessler, S. H., Reifegerste, D., \& Guenther, L. (2016). Die Evidenzkraft von Bildern in der Wissenschaftskommunikation [On the power of visuals in scientific communication]. In G. Ruhrmann, S. H. Kessler, \& L. Guenther (Eds.), Wissenschaftskommunikation zwischen Risiko und (Un-)Sicherheit [Science communication between risk and (un)certainty] (pp. 171-192). Cologne: Herbert von Halem.

Kessler, S. H., \& Zillich, A. F. (2018). Searching online for information about vaccination: Assessing the influence of user-specific cognitive factors using eye- tracking. Health Communication, 34(10), 1150-1158. https://doi.org/10.1080/10410236.2018.1465793

Kim, S., Pjesivac, I., \& Jin, Y. (2019). Effects of message framing on influenza vaccination: Understanding the role of risk disclosure, perceived vaccine efficacy, and felt ambivalence. Health Communication, 34(1), 21-30. https://doi.org/10.1080/10410236. 2017.1384353

Koinig, I., Diehl, S., \& Mueller, B. (2017). Are pharmaceutical ads affording consumers a greater say in their health care? The evaluation and self-empowerment effects of different ad appeals in Brazil. International Journal of Advertising, 36(6), 945-974. https://doi. org/10.1080/02650487.2017.1367353

Kreuter, M. W., Strecher, V. J., \& Glassman, B. (1999). One size does not fit all: The case for tailoring print materials. Annals of Behavioral Medicine, 21(4), 276-283.

Kreuter, M. W., \& Wray, R. J. (2003). Tailored and targeted health communication: Strategies for enhancing information relevance. American Journal of Health Behavior, 27(Suppl. 3), 227-232.

Lee, S. Y., Hwang, H., Hawkins, R., \& Pingree, S. (2008). Interplay of negative emotion and health self-efficacy on the use of health information and its outcomes. Communication Research, 35(2), 358-381.

Lee, M. K., Whitehill King, K., \& Reid, L. N. (2015). Factors influencing consumers' attitudinal and behavioral responses to direct-to-consumer and over-the-counter drug advertising. Journal of Health Communication, 20(4), 431-444.

Leiner, D. J. (2016). Our research's breadth lives on convenience samples. A case study of the online respondent pool "SoSci Panel." SCM Studies in Communication and Media, 5(4), 367-396.

Lindgren, E., \& Gustafson, R. (2001). Tick-borne encephalitis in Sweden and climate change. The Lancet, 358(9275), 16-18.

Lobinger, K. (2012). Visuelle Kommunikationsforschung. Medienbilder als Herausforderung für die Kommunikations-und Medienwissenschaft [Visual communication research: Media images as a challenge for communication and media studies]. Wiesbaden: Springer.

MacDonald, N. E. (2015). Vaccine hesitancy: Definition, scope and determinants. Vaccine, 33(34), 4161-4164. https://doi.org/10.1016/j.vaccine.2015. 04.036

Maibach, E. W., Weber, D., Massett, H., Hancock, G. R., \& Price, S. (2006). Understanding consumers' health information preferences: Development and validation of a brief screening instruments. Journal of Health Communication, 11(8), 717-736.

Marks, R., Allegrante, J. P., \& Lorig, K. (2005). A review and synthesis of research evidence for self-efficacyenhancing interventions for reducing chronic disability: Implications for health education practice (Part II). Health Promotion Practice, 6(2), 148-156. 
Matthes, J., \& Kohring, M. (2008). The content analysis of media frames: Towards improving reliability and validity. Journal of Communication, 58(2), 258-279. https://doi.org/10.1111/j.1460-2466.2008.00384.x

McRee, A.-L., Reiter, P. L., Chantala, K., \& Brewer, N. T. (2010). Does framing human papillomavirus vaccine as preventing cancer in men increase vaccine acceptability? Cancer Epidemiology, Biomarkers \& Prevention, 19(8), 1937-1944. https://doi.org/10.1158/ 1055-9965.EPI-09-1287

Moorman, C., \& Matulich, E. (1993). A model of consumers' preventive health behaviors: The role of health motivation and health ability. Journal of Consumer Research, 20(2). 208-228. https://doi.org/ 10.1086/209344

Nan, X., Daily, K., Richards, A., \& Holt, C. (2019). Parental support for HPV vaccination mandates among African Americans: The impact of message framing and consideration of future consequences. Health Communication, 34(12), 1404-1412. https:// doi.org/10.1080/10410236.2018.1493419

Niederdeppe, J., Hornik, R., Kelly, B., Frosch, D., Romantan, A., Stevens, R., . . Schwarz, S. (2007). Examining the dimensions of cancer-related information scanning and seeking behavior. Health Communication, 22(2), 153-167.

Nutbeam, D. (1998). Health promotion glossary. Health Promotion International, 13(4), 349-364. https://doi. org/10.1093/heapro/13.4.349

Nyhan, B., \& Reifler, J. (2015). Does correcting myths about the flu vaccine work? An experimental evaluation of the effects of corrective information. Vaccine, 33(3), 459-464. https://doi.org/10.1016/ j.vaccine.2014.11.017

Österreichischer Rundfunk. (2015). Schutz vor Zecken [Protection against tick bites]. Guten Morgen Österreich. Retrieved from https://tv.orf.at/gutenmorgen/ stories/2851717

Reese, S. D. (2010). Finding frames in a web of culture: The case of war on terror. In P. D'Angelo \& J. A. Kuypers (Eds.), Doing news framing analysis: Empirical and theoretical perspectives (pp. 17-42). New York, NY: Routledge.

Ruhrmann, G., Guenther, L., \& Kessler, S. H. (2015). Frames of scientific evidence: How journalists represent the (un)certainty of molecular medicine in science television programs. Public Understanding of Science, 24(6), 681-696. https://doi.org/10.1177/ 0963662513510643

Schoeppe, J., Cheadle, A., Melton, M., Faubion, T., Miller, C., Matthys, J., \& Hsu, C. (2017). The immunity community: A community engagement strategy for reducing vaccine hesitancy. Health Promotion Practice, 18(5), 654-661. https://doi.org/10.1177/ 1524839917697303

Shapiro, G. K., Tatar, O., Dube, E., Amsel, R., Knauper, B., Naz, A., . . . Rosberger, Z. (2018). The vaccine hesitancy scale: Psychometric properties and valida- tion. Vaccine, 36, 660-667. https://doi.org/10.1016/ j.vaccine.2017.12.043

Shim, M., Kelly, B., \& Hornik, R. (2006). Cancer information scanning and seeking behavior is associated with knowledge, lifestyle choices, and screening. Journal of Health Communication, 11(1), 157-172.

Smit, R. (2012). Cost-effectiveness of tick-borne encephalitis vaccination in Slovenian adults. Vaccine, 30(44), 6301-6306. https://doi.org/10.1016/ j.vaccine.2012.07.083

So, J., \& Nabi, R. (2013). Reduction of perceived social distance as an explanation for media's influence on personal risk perceptions: A test of the risk convergence model. Human Communication Research, 39(3), 317-338. https://doi.org/10.1111/hcre.12005

Stark, A. P., Edmonds, R., \& Quinn, S. (2007). Eyetracking the news: A study of print and online reading. St. Petersburg, FL: The Poynter Institute.

Statista. (2019). Besitzen Sie einen Impfschutz gegen FSME? [Are you vaccinated against TBE?]. Statista. Retrieved from https://de.statista.com/ statistik/daten/studie/550913/umfrage/umfrage-inoesterreich-zur-aktualitaet-der-fsme-impfung

Strekalova, Y. A. (2014). Informing dissemination research: A content analysis of U.S. newspaper coverage of medical nanotechnology news. Science Communication, 37(2), 151-172. https://doi.org/ $10.1177 / 1075547014555025$

Tversky, A., \& Kahneman, D. (1981). The framing of decisions and the psychology of choice. Science, 211(4481), 453-458.

van der Molen, B. (1999). Relating information needs to the cancer experience: Information as a key coping strategy. European Journal of Cancer Care, 8(4), 238-244.

World Health Organization. (2011). Vaccines against tickborne encephalitis: WHO position paper. Weekly Epidemological Report, 86(24), 241-256. Retrieved from https://www.who.int/wer/2011/wer8624.pdf?ua=1

World Health Organization. (2014). Report of the SAGE working group on vaccine hesitancy. Geneva: World Health Organization. Retrieved from https:// www.who.int/immunization/sage/meetings/2014/ october/1_Report_WORKING_GROUP_vaccine_ hesitancy_final.pdf

Wiseman, R., \& Watt, C. (2004). Measuring superstitious belief: Why lucky charms matter. Personal Individual Differences, 37(8), 1533-1541.

Zagaria, M. A. E. (2004). Low health literacy: Raising awareness for optimal health communication. U.S. Pharmacist, 10, 41-48.

Zavadska, D., Odzelevica, Z., Karelis, G., Liepina, L., Litauniece, Z. A., Bormane, A., \& Schmitt, H.-J. (2018). Tick-borne encephalitis: A 43-year summary of epidemiological and clinical data from Latvia (1973 to 2016). PloS One, 13(11), e0204844. https://doi.org/ 10.1371/journal.pone.0204844 


\section{About the Authors}

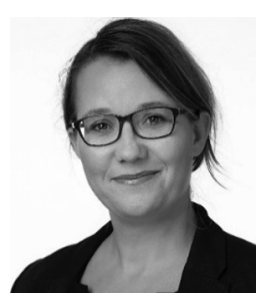

Sarah Kohler (PhD) is a Postdoctoral Researcher at the Department of Science Communication at the Karlsruhe Institute of Technology, Germany. She studied Communication Science with a focus on Strategic Communication at the University of Muenster, Germany, and worked as Senior Scientist at the University of Klagenfurt, Austria. Her research interests cover science communication, empirical research and methods, media use, and media effects.

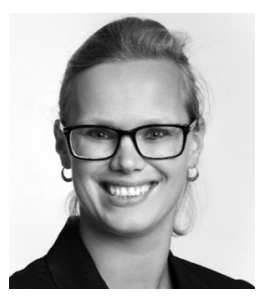

Isabell Koinig (PhD, University of Klagenfurt, Austria) is a Postdoctoral Researcher at the Department of Media and Communications at the University of Klagenfurt, Austria. Her research interests predominantly concern the fields of health communication (pharmaceutical advertising, eHealth/mHealth, health for sustainable development, and wearables), intercultural advertising, organizational health, as well as media and convergence management. 